\title{
A Corporate Reputation Propagation Dynamic Model
}

\author{
Yufeng Wang, ${ }^{1}$ Xu Yang $\mathbb{D},{ }^{1}$ Yanyou Chai $\mathbb{D}^{2}{ }^{2}$ Xuguang Yang, ${ }^{3}$ and Qi Tian ${ }^{2}$ \\ ${ }^{1}$ School of Economics and Management, Harbin Engineering University, Harbin 150001, Heilongjiang, China \\ ${ }^{2}$ College of Mathematical Sciences, Harbin Engineering University, Harbin 150001, Heilongjiang, China \\ ${ }^{3}$ School of Information Engineering, Long Dong University, Qingyang 745000, Gansu, China
}

Correspondence should be addressed to Xu Yang; yxu1969@163.com and Yanyou Chai; chaiyanyou@hrbeu.edu.cn

Received 2 August 2021; Revised 7 October 2021; Accepted 12 October 2021; Published 27 October 2021

Academic Editor: M Syed Ali

Copyright ( 2021 Yufeng Wang et al. This is an open access article distributed under the Creative Commons Attribution License, which permits unrestricted use, distribution, and reproduction in any medium, provided the original work is properly cited.

\begin{abstract}
This study analyzes the process of corporate reputation (CR) propagation. We consider that different positions play different roles via social word of mouth (sWOM). In essence, our interest lies in the following question: how does sWOM affect the process of CR propagation? As a benchmark, we develop a dynamic model to reflect the factors and laws influencing corporate reputation propagation. We find that the stability of the system is not what corporations want to see in the propagation of positive CR after analyzing two basic reproduction numbers and conducting a numerical simulation. Another important finding is that stability is what corporations expect in the propagation of negative CR. This study makes the logical analysis of the relationship between CR and consumer loyalty more complete and helps us to clearly understand the overall process of CR propagation. The study provides a new way to analyze the law of CR propagation and can provide a reference for decision-making for corporations.
\end{abstract}

\section{Introduction}

Corporate reputation (CR) is an intangible asset [1] and a cognitive source of competitive advantage that is related to the sustainable development of corporations. It is unique and inimitable according to Resource-Based Theory [2-5]. The definition of CR is a collective assessment of a corporation's attractiveness to a specific group of stakeholders relative to a reference group of corporations with which the corporation competes for resources [6]. "Attractiveness" relates to a set of consumers' emotional attributes that are highly correlated. Positive word of mouth delivers effective value perceptions from the perspective of a theory of consumption values [7]. The "Digital 2020 report" published by We Are Social and Hootsuite showed that 4.54 billion people now use the Internet, with nearly $60 \%$ of the world's population already online. The most remarkable numbers in the report were that $97 \%$ of users stated that they had visited or used a social network or messaging service in the past month, $90 \%$ of users had visited an online retail store on the web, $74 \%$ users had purchased a product online, and the average amount of time per day spent using social media was 2 hours and 24 minutes [8]. Social word of mouth (sWOM) as a subset of electronic word of mouth (eWOM) affects consumer behaviors deeply [9]. In particular, the "Digital 2020 report" also showed that the number of social media users passed the 3.8 billion mark in January 2020 [7]. This means that "your online reputation is your reputation" [10-12].

Corporate reputation is the result of group perception [13]. Rosario researched 1532 effect sizes across 96 studies covering 40 platforms and 26 product categories and found that sWOM has a stronger effect on sales for tangible goods that are new to the market [14]. Meanwhile, consumer trust and satisfaction positively convey trust in corporate reputation $[15,16]$. The antecedents that cause consumers to write reviews are motivation, gender influence, cognitive and psychological aspects, satisfaction/dissatisfaction, group influence, sense of community belonging, and elements related to service quality and helping others and/or corporations $[17,18]$. These reviews affect new consumers' purchases, decision-making models, repurchase intentions, and loyalty, among others [19]. In addition, the influence of heuristic judgments in social media affects CR [20]. SWOM has been shown to have a strong effect on the decisionmaking processes of consumers on consumer review 
websites $[21,22]$. SWOM is transmitted through a variety of electronic communication channels: discussion boards, corporate websites, blogs, e-mails, chat rooms, or instant messaging, Twitter, Facebook, review websites, and newsgroups [23-26]. Social media influencers can influence potential consumers' purchase intentions via sWOM $[27,28]$. In particular, good sWOM can increase consumers' trust in corporations $[29,30]$ and create good business value. The more confidence people have that actual consumers produce positive online reviews, the more favorably they rate the business and the more likely they are to recommend the business to others [31]. The changing ways in which audiences express their evaluations and the increasing heterogeneity and dynamism of characterizing media reputations influence the formation of organizational reputations [12]. People connect with themselves and those outside them through social media. Because of this connection and interaction, people interact with each other's behaviors and emotions [32]. The impact of this connection is very powerful. Positive sWOM increases social support, consumer loyalty behaviors, employer branding, and corporate environmental performance [33-35].

Previous studies have mainly focused on the antecedents and consequences of sWOM [36, 37] on CR. They paid particular attention to three points: social media content [38], corporate social responsibility (CSR) [39], and user perceptions [40] and user-generated content [41]. However, there has been little research on the $\mathrm{CR}$ propagation process by social word of mouth (sWOM). From the perspective of corporations, they hope that their good reputation will be widely propagated. In this way, the goods or services of these corporations can be purchased by more consumers, and the corporations can also obtain more profit. In this paper, we build a dynamic model to analyze the law of CR propagation from the perspective of sWOM. This is essential and can provide a reference for decision-making for corporations.

\section{CR Propagation Model}

Wood and Muñoz define sWOM communication as any visual or textual post about a corporation or their product offering that is either created independently by a consumer, or created by a corporation, or created by a consumer in collaboration with a corporation and publicly shared on a personal or corporate social media account [9]. In the process of CR propagation based on sWOM, it is possible for people to assume the role of a disseminator repeatedly, depending on the changes in the individual's cognition. Consumers use social media to identify and share information. When a potential consumer contacts a follower and views a positive $\mathrm{CR}[27,28]$, they may turn into a new follower. However, if a potential consumer contacts a resister and views a negative $C R$, then they may turn to a new resister.

Let $N(t)$ denote the total population of a region at time $t$. We divide the total population into three classes: "potential consumers" $(P(t))$, "followers" $(F(t))$, and "resisters" $(R(t))$ of a corporation. For example, many people are enthusiastic followers of Apple's mobile phones because of their advantages of good system optimization, high efficiency, and smooth operation. When a new Apple phone comes onto the market, they will buy it as soon as possible, even if their existing one can still be used effectively. On the other hand, some people are "resisters": they not only will not buy corporate products but also may persuade potential consumers not to do so. Furthermore, some followers may turn into resisters because they have a bad experience with products they buy or read negative news. For instance, the news item "iPhone battery explodes at Zurich apple store, one injured" [42] appeared on TRENDING NEWS on January 10, 2018. The news was heavily transmitted on social media; some followers became hurt emotionally, lost their trust in Apple, and stopped being followers of the company.

According to the above analysis, we constructed a CR propagation model to study the dynamic laws of $P(t), F(t)$, and $R(t)$, called the "PFR" model. First, we considered the propagation of CR with a variable population size and assumed that CR propagates in a population with constant immigration and emigration. All recruitment was into the potential class and occurred at a positive constant rate $\varepsilon$, with $\mu$ being the emigration rate of those three classes.

As shown in Figure 1, the CR propagation PFR model can be summarized as follows:

(i) When a potential consumer contacts a resister, the former turns into a new resister with probability $\alpha$. Similarly, when a potential consumer contacts a follower, the former turns into a new follower with probability $\beta$.

(ii) If some followers have bad experiences with the products or see reports of major defects in a brand's products, even if they do not find the defects themselves in the product they are using, they may consider no longer buying the brand's products and turn into resisters with probability $\gamma$.

(iii) Once a potential consumer becomes a resister, no matter how the merchant advertises and promotes itself, it is almost impossible for him/her to become a follower of the corporation or even a neutral consumer.

The main parameters and decision variables used in the analyses are summarized in Table 1.

The system describing the dynamics of CR propagation can be given by the following ordinary differential equations:

$$
\left\{\begin{array}{l}
\frac{\mathrm{d} P}{\mathrm{~d} t}=\varepsilon-\alpha P R-\beta P F-\mu P, \\
\frac{\mathrm{d} F}{\mathrm{~d} t}=\beta P F-(\gamma+\mu) F, \\
\frac{\mathrm{dR}}{\mathrm{d} t}=\gamma F+\alpha P R-\mu R,
\end{array}\right.
$$

where $\quad \varepsilon>0, \alpha>0, \beta>0, \gamma>0, \mu>0$, and

$P(t)+F(t)+R(t)=N(t)$. 
It is easy to see that $\mathrm{dN} / \mathrm{dt}=\varepsilon-\mu N$, so $N(t)=\left(N_{0}-\varepsilon / \mu\right) e^{-\mu t}+\varepsilon / \mu$, where $N_{0}=N(0)$ and then $\lim _{t \rightarrow \infty} N(t)=\varepsilon / \mu$. The positive invariant set of system (1) is

$$
\Gamma=\left\{(P, F, R): P+F+R \leq \frac{\varepsilon}{\mu}, P>0, F>0, R>0\right\} .
$$

\section{Theoretical Analysis}

3.1. Existence of Equilibriums. According to system (1), the equilibriums satisfy

$$
\left\{\begin{array}{l}
\mathcal{E}-\alpha P R-\beta P F-\mu P=0, \\
\beta P F-(\gamma+\mu) F=0, \\
\gamma F+\alpha P R-\mu R=0 .
\end{array}\right.
$$

Thus, system (1) has the following equilibriums:

$$
\begin{aligned}
& E_{1}=\left(\frac{\varepsilon}{\mu}, 0,0\right), \\
& E_{2}=\left(\frac{\mu}{\alpha}, 0, \frac{\varepsilon}{\mu}-\frac{\mu}{\alpha}\right), \\
& E_{3}=\left(\frac{\gamma+\mu}{\beta}, \frac{[(\alpha-\beta) \mu+\alpha \gamma]\left(\mu^{2}+\gamma \mu-\beta \varepsilon\right)}{\beta \mu(\alpha-\beta)(\gamma+\mu)}, \frac{\gamma\left(\mu^{2}+\gamma \mu-\beta \varepsilon\right)}{(\alpha-\beta) \mu(\gamma+\mu)}\right),
\end{aligned}
$$

where $E_{1}$ and $E_{2}$ are the reputation-free equilibriums (RFEs).

3.2. Stability of Equilibriums. Many epidemic models have a disease-free equilibrium (DFE) at which the population remains in the absence of disease. These models usually have a threshold parameter, known as the basic reproduction number $R_{0}$, such that if $R_{0}<1$, then the DFE is locally asymptotically stable and the disease cannot invade the population; however, if $R_{0}>1$, then the DFE is unstable and invasion is always possible [43, 44]. Similarly, we can define the basic reproduction number of the CR propagation model, which has a similar meaning to epidemic models.

Now, we use the next-generation matrix method to calculate the basic reproduction number for model (1). Let

$$
\begin{gathered}
\mathscr{F}(P, F, R)=\left[\begin{array}{c}
\beta P R \\
0 \\
0
\end{array}\right], \\
\mathscr{V}(P, F, R)=\left[\begin{array}{c}
(\gamma+\mu) F \\
\alpha P R+\beta P F+\mu P-\varepsilon \\
\mu R-\gamma F-\alpha P R
\end{array}\right] .
\end{gathered}
$$

Then,

$$
\begin{aligned}
& \mathrm{D} \mathscr{F}(P, F, R)=\left[\begin{array}{ccc}
\beta F & \beta P & 0 \\
0 & 0 & 0 \\
0 & 0 & 0
\end{array}\right], \\
& \mathrm{D} \mathscr{V}(P, F, R)=\left[\begin{array}{ccc}
0 & \gamma+\mu & 0 \\
\alpha R+\beta F+\mu & \beta P & \alpha P \\
-\alpha R & -\gamma & \mu-\alpha P
\end{array}\right] .
\end{aligned}
$$

At RFE $E_{1}$, let

$$
\begin{aligned}
& F_{1}=D \mathscr{F}\left(\frac{\varepsilon}{\mu}, 0,0\right)=\left[\begin{array}{lll}
0 & \frac{\beta \varepsilon}{\mu} & 0 \\
0 & 0 & 0 \\
0 & 0 & 0
\end{array}\right], \\
& V_{1}=D \mathscr{V}\left(\frac{\varepsilon}{\mu}, 0,0\right)=\left[\begin{array}{lll}
0 & \gamma+\mu & 0 \\
\mu & \frac{\beta \varepsilon}{\mu} & \frac{\alpha \varepsilon}{\mu} \\
0 & -\gamma & \mu-\frac{\alpha \varepsilon}{\mu}
\end{array}\right] .
\end{aligned}
$$

Thus, at RFE $E_{1}$, the basic reproduction number $R_{01}$ is

$$
R_{01}=\rho\left(F_{1} V_{1}^{-1}\right)=\frac{\beta \varepsilon}{\mu(\gamma+\mu)} .
$$

At RFE $E_{2}$, let

$F_{2}=D \mathscr{F}\left(\frac{\mu}{\alpha}, 0, \frac{\varepsilon}{\mu}-\frac{\mu}{\alpha}\right)=\left[\begin{array}{ccc}0 & \frac{\beta \mu}{\alpha} & 0 \\ 0 & 0 & 0 \\ 0 & 0 & 0\end{array}\right]$,

$V_{2}=D \mathscr{V}\left(\frac{\mu}{\alpha}, 0, \frac{\varepsilon}{\mu}-\frac{\mu}{\alpha}\right)=\left[\begin{array}{ccc}0 & \gamma+\mu & 0 \\ \frac{\alpha \varepsilon-\mu^{2}}{\mu}+\mu & \frac{\beta \mu}{\alpha} & \mu \\ -\frac{\alpha \varepsilon-\mu^{2}}{\mu} & -\gamma & 0\end{array}\right]$.

Thus, at RFE $E_{2}$, the basic reproduction number $R_{02}$ is

$$
R_{02}=\rho\left(F_{2} V_{2}^{-1}\right)=\frac{\beta \mu}{\alpha(\gamma+\mu)} .
$$

The Jacobian matrix of system (1) is 


$$
J=\left[\begin{array}{ccc}
-R \alpha-F \beta-\mu & -P \beta & -P \alpha \\
F \beta & P \beta-\gamma-\mu & 0 \\
R \alpha & \gamma & P \alpha-\mu
\end{array}\right] .
$$

Theorem 1. If $R_{01}<1$ and $\mu>\sqrt{\alpha \varepsilon}$, the RFE $E_{1}$ is locally asymptotically stable.

Proof. The Jacobian matrix of system (1) at $E_{1}=(\varepsilon / \mu, 0,0)$ is

$$
J\left(E_{1}\right)=\left[\begin{array}{ccc}
-\mu & -\frac{\beta \varepsilon}{\mu} & -\frac{\alpha \varepsilon}{\mu} \\
0 & \frac{\beta \varepsilon}{\mu}-(\gamma+\mu) & 0 \\
0 & \gamma & \frac{\alpha \varepsilon}{\mu}-\mu
\end{array}\right] .
$$

Then, we find that $J\left(E_{1}\right)$ always has three real eigenvalues: $\quad h_{11}=(\beta \varepsilon / \mu)-(\gamma+\mu), \quad h_{12}=(\alpha \varepsilon / \mu)-\mu$, and $h_{13}=-\mu$.

When $R_{01}=\beta \varepsilon / \mu(\gamma+\mu)<1, \quad h_{11}=\beta \varepsilon / \mu-(\gamma+\mu)<0$; when $\mu>\sqrt{\alpha \varepsilon}, h_{12}=\alpha \varepsilon / \mu-\mu<0$; and $h_{13}=-\mu<0$. Thus, when $R_{01}<1$ and $\mu>\sqrt{\alpha \varepsilon}, h_{11}, h_{12}, h_{13}<0$, according to the Routh-Hurwitz stability criterion, RFE $E_{1}$ is locally asymptotically stable.

Theorem 2. If $\mu<\sqrt{\alpha \varepsilon}$ and $R_{02}<1, R F E E_{2}$ is a positive semitrivial steady-state solution and is locally asymptotically stable.

Proof. Obviously, when $\mu<\sqrt{\alpha \varepsilon}$, RFE $E_{2}=(\mu / \alpha, 0, \varepsilon / \mu-$ $\mu / \alpha)$ is a positive semitrivial steady-state solution.

The Jacobian matrix of system (1) at $E_{2}=(\mu / \alpha, 0, \varepsilon / \mu-$ $\mu / \alpha)$ is

$$
J\left(E_{2}\right)=\left[\begin{array}{ccc}
-\frac{\varepsilon \alpha}{\mu} & -\frac{\beta \mu}{\alpha} & -\mu \\
0 & -\frac{\alpha(\gamma+\mu)-\beta \mu}{\alpha} & 0 \\
\frac{\varepsilon \alpha-\mu^{2}}{\mu} & \gamma & 0
\end{array}\right] .
$$

Then, we find that $J\left(E_{2}\right)$ always has three real eigenvalues: $\quad h_{21}=-\alpha \varepsilon-\mu^{2} / \mu, \quad h_{22}=-\alpha(\gamma+\mu)-\beta \mu / \alpha$, and $h_{23}=-\mu$.

When $\quad \mu<\sqrt{\alpha \varepsilon}, \quad h_{21}=-\alpha \varepsilon-\mu^{2} / \mu<0$; when $R_{02}=\beta \mu / \alpha(\gamma+\mu)<1, \quad h_{22}=-\alpha(\gamma+\mu)-\beta \mu / \alpha<0 ; \quad$ and $h_{23}=-\mu<0$. Thus, when $\mu<\sqrt{\alpha \varepsilon}$ and $R_{02}<1$, $h_{21}, h_{22}, h_{23}<0$, according to the Routh-Hurwitz stability criterion, RFE $E_{2}$ is locally asymptotically stable.
Theorem 3. If $\alpha>\beta$ and $\mu>1 / 2\left(-\gamma+\sqrt{4 \beta \varepsilon+\gamma^{2}}\right)$, equilibrium $E_{3}$ is a positive equilibrium and is unstable.

Proof. If $\alpha>\beta$, let $\gamma\left(\mu^{2}+\gamma \mu-\beta \varepsilon\right) /(\alpha-\beta) \mu(\gamma+\mu)>0$, and we can get $\mu>1 / 2\left(-\gamma+\sqrt{4 \beta \varepsilon+\gamma^{2}}\right)$. When $\gamma\left(\mu^{2}+\gamma \mu-\right.$ $\beta \varepsilon) /(\alpha-\beta) \mu(\gamma+\mu)>0, \quad[(\alpha-\beta) \mu+\alpha \gamma]\left(\mu^{2}+\gamma \mu-\beta \varepsilon\right) / \beta \mu$ $(\alpha-\beta)(\gamma+\mu)>0$. Thus, when $\alpha>\beta$ and $\mu>1 / 2(-\gamma+$ $\left.\sqrt{4 \beta \varepsilon+\gamma^{2}}\right)$, the equilibrium $E_{3}=(\gamma+\mu / \beta,[(\alpha-\beta) \mu+\alpha \gamma]$ $\left(\mu^{2}+\gamma \mu-\beta \varepsilon\right) / \beta \mu(\alpha-\beta)(\gamma+\mu), \gamma\left(\mu^{2}+\gamma \mu-\beta \varepsilon\right) / \quad(\alpha-\beta) \mu$ $(\gamma+\mu))$ is positive.

The Jacobian matrix of system (1) at $E_{3}$ is

$$
J\left(E_{3}\right)=\left[\begin{array}{ccc}
-\frac{\varepsilon \beta}{\gamma+\mu} & -(\gamma+\mu) & -\frac{\alpha(\gamma+\mu)}{\beta} \\
-\frac{[(\alpha-\beta) \mu+\alpha \gamma]\left(\mu^{2}+\gamma \mu-\beta \varepsilon\right)}{(\alpha-\beta) \mu(\gamma+\mu)} & 0 & 0 \\
\frac{\alpha \gamma\left(\mu^{2}+\gamma \mu-\beta \varepsilon\right)}{(\alpha-\beta) \mu(\gamma+\mu)} & \gamma & \frac{(\alpha-\beta) \mu+\alpha \gamma}{\beta}
\end{array}\right] \text {. }
$$

The characteristic polynomial of $J\left(E_{3}\right)$ is

$$
\begin{aligned}
\left|h-J\left(E_{3}\right)\right| & =\left|\begin{array}{ccc}
h+\frac{\beta \varepsilon}{\gamma+\mu} & \gamma+\mu & \frac{\alpha(\gamma+\mu)}{\beta} \\
\frac{[(\alpha-\beta) \mu+\alpha \gamma]\left(\mu^{2}+\gamma \mu-\beta \varepsilon\right)}{(\alpha-\beta) \mu(\gamma+\mu)} & h & 0 \\
-\frac{\alpha \gamma\left(\mu^{2}+\gamma \mu-\beta \varepsilon\right)}{(\alpha-\beta) \mu(\gamma+\mu)} & -\gamma & h-\frac{(\alpha-\beta) \mu+\alpha \gamma}{\beta}
\end{array}\right| \\
& =(h+\mu)\left(h^{2}+b_{1} h+b_{0}\right),
\end{aligned}
$$

where $b_{1}=\beta^{2} \varepsilon-\alpha(\gamma+\mu)^{2} / \beta(\gamma+\mu)$ and $b_{0}=[(\alpha-\beta) \mu$ $+\alpha \gamma]\left(\mu^{2}+\gamma \mu-\beta \varepsilon\right) / \beta \mu$.

Equilibrium $E_{3}$ is positive, so $b_{0}>0$.

One eigenvalue of $J\left(E_{3}\right)$ is $h_{31}=-\mu$. Next, we discuss the other two eigenvalues of the Jacobian matrix $J\left(E_{3}\right)$ by discussing the roots of the quadratic equation $h^{2}+b_{1} h+b_{0}=0$.

When $\alpha>\beta$ and $\mu>1 / 2\left(-\gamma+\sqrt{4 \beta \varepsilon+\gamma^{2}}\right), \gamma\left(\mu^{2}+\gamma \mu-\right.$ $\beta \varepsilon) /(\alpha-\beta) \mu(\gamma+\mu)>0$, then $\beta \varepsilon<\mu(\gamma+\mu)$, so

$$
\begin{aligned}
b_{1} & =\frac{\beta^{2} \varepsilon-\alpha(\gamma+\mu)^{2}}{\beta(\gamma+\mu)}<\frac{\beta \mu(\gamma+\mu)-\alpha(\gamma+\mu)^{2}}{\beta(\gamma+\mu)} \\
& =-\frac{(\alpha-\beta) \mu+\alpha \gamma}{\beta}<0 .
\end{aligned}
$$

(1) If $\Delta=b_{1}^{2}-4 b_{0}>0, \quad h_{32}=-b_{1}+\sqrt{b_{1}^{2}-4 b_{0}} / 2>0$. According to the Routh-Hurwitz stability criterion, equilibrium $E_{3}$ is unstable.

(2) If $\Delta=b_{1}^{2}-4 b_{0}=0, h_{32}=h_{33}=-b_{1} / 2>0$. According to the Routh-Hurwitz stability criterion, equilibrium $E_{3}$ is also unstable. 
(3) If $\Delta=b_{1}^{2}-4 b_{0}<0$, the real parts of the other two complex eigenvalues $h_{32}, h_{33}$ of $J\left(E_{3}\right)$ are $-b_{1} / 2>0$. According to the Routh-Hurwitz stability criterion, equilibrium $E_{3}$ is also unstable.

Thus, we complete the proof.

Theorem 4. If $\beta>\alpha$ and $\mu<\min \left\{1 / 2\left(-\gamma+\sqrt{4 \beta \varepsilon+\gamma^{2}}\right)\right.$, $\alpha \gamma / \beta-\alpha\}$, equilibrium $E_{3}$ is positive and unstable.

Proof. If $\beta>\alpha$, let $\gamma\left(\mu^{2}+\gamma \mu-\beta \varepsilon\right) /(\alpha-\beta) \mu(\gamma+\mu)>0$; we can get $\mu<1 / 2\left(-\gamma+\sqrt{4 \beta \varepsilon+\gamma^{2}}\right)$. When $\gamma\left(\mu^{2}+\gamma \mu-\beta \varepsilon\right)$ $/(\alpha-\beta) \mu(\gamma+\mu)>0$ and $\mu<\alpha \gamma / \beta-\alpha,[(\alpha-\beta) \mu+\alpha \gamma]\left(\mu^{2}+\right.$ $\gamma \mu-\beta \varepsilon) \quad / \beta \mu(\alpha-\beta)(\gamma+\mu)>0$. Thus, when $\beta>\alpha$ and $\mu<\min \left\{1 / 2\left(-\gamma+\sqrt{4 \beta \varepsilon+\gamma^{2}}\right), \alpha \gamma / \beta-\alpha\right\}$, equilibrium $E_{3}$ is a positive equilibrium.

The Jacobian matrix of system (1) at $E_{3}$ is the same as equation (15). The characteristic polynomial of $J\left(E_{3}\right)$ is the same as equation (17).

Equilibrium $E_{3}$ is a positive equilibrium, so $b_{0}<0$.

One eigenvalue of $J\left(E_{3}\right)$ is $h_{31}=-\mu$. Next, we discuss the other two eigenvalues of the Jacobian matrix $J\left(E_{3}\right)$ by discussing the roots of the quadratic equation $h^{2}+b_{1} h+b_{0}=0$ :

(1) If $b_{1}=0$, because $b_{0}<0$, the equation $h^{2}+b_{1} h+b_{0}=$ 0 has a positive root. According to the Routh-Hurwitz stability criterion, equilibrium $E_{3}$ is unstable.

(2) If $b_{1} \neq 0$ because $b_{0}<0, \Delta=b_{1}^{2}-4 b_{0}>0$. As a result, whether $b_{1}$ is positive or not, the equation $h^{2}+b_{1} h+$ $b_{0}=0$ has a positive root $h_{32}=-b_{1}+\sqrt{b_{1}^{2}-4 b_{0}} / 2>0$. According to the Routh-Hurwitz stability criterion, equilibrium $E_{3}$ is unstable.

Thus, we complete the proof.

\section{Numerical Simulation}

4.1. Stability of the System about $E_{1}$. Let $\varepsilon=1, \alpha=0.002, \beta=0.0025, \gamma=0.02, \mu=0.045$. According to (9), we obtain $R_{01}=0.8547<1$. The relationship among these parameters satisfies the condition of Theorem 1 . Then, Figure 2 depicts the local asymptotic stability of system (1) about $E_{1}$. From Figure 2, we can see that, over time, the number of potential consumers will tend to be constant $(\varepsilon / \mu=22.22)$, while the number of followers and resisters will tend to be 0 . In this case, neither a positive nor a negative $\mathrm{CR}$ has been effectively propagated, and all consumers tend to be neutral. This is the case with many original equipment manufacturers in China. For example, Homa Group is one of the largest refrigerator OEM factories in the world, with eight production bases and an annual capacity of over 12 million units. Homa Group has been the refrigerator export champion in China for 12 consecutive years. However, the vast majority of ordinary consumers do not know this brand at all and tend to be neutral. Because of its business positioning, Homa Group does not pay attention to brand promotion among ordinary consumers.
Let $\varepsilon=1, \alpha=0.002, \beta=0.1, \gamma=0.02, \mu=0.045$; thus, we obtain $R_{01}=48.3092>1$. Then, Figure 3 depicts the instability of system (1) about $E_{1}$. From Figure 3, we can see that, over time, the number of followers will tend to be constant at less than and very close to $\varepsilon / \mu=22.22$, while the number of potential consumers and resisters will tend to be constant at greater than and close to 0 , respectively. In this case, a positive CR has been effectively propagated.

Figure 2 shows that the propagation of $\mathrm{CR}$ lies in the stability of the system; the number of followers tends to be 0 . However, this is not what a corporation hopes to see, as corporations are eager to gain large numbers of followers. Thus, potential consumers should turn into followers, improving profits, and the value of $R_{01}$ should therefore be bigger. When $R_{01}=48.3092 \gg 1$ (Figure 3), the result shows that the number of followers grows rapidly. The value of $R_{01}$ is mainly determined by $\beta$ and $\gamma$. If a corporation wants to accelerate the propagation of their positive CR, then it should take effective measures to expand the influence of followers and improve product quality and service to maintain follower loyalty at a higher level. In China, there is such a corporation named ERKE. In July 2021, a catastrophic flood occurred in Henan Province, China. Some cities are flooded, and the streets become an ocean. Erke donated 50 million yuan of materials to support Henan's disaster resistance, but many social media users were worried about Erke's poor performance and still made large donations, shouting heartache one after another. The microblog hot search has reached 700 million times of reading and more than 137000 discussions. Erke's official donations, graphic forwarding volume, and comments also exceeded 200000. In addition to microblog's message, they spontaneously entered Erke's Taobao live room and TikTok live room to buy Erke's products. As of July 23, the number of fans in Erke's Taobao live studio had increased to 7.526 million, with 389000 likes, and the data was still growing further.

4.2. Stability of the System about $E_{2}$. Let $\varepsilon=1, \alpha=$ $0.003, \beta=0.003, \gamma=0.001, \mu=0.045$. According to equation (11), we have $R_{02}=0.9783<1$. The relationships among these parameters satisfy the conditions of Theorem 2. Figure 4 depicts the local asymptotic stability of system (1) about $E_{2}$. From Figure 4, we can see that, over time, the numbers of potential consumers, followers, and resisters will tend to be positive in the semitrivial steady-state solution $E_{2}$. In this case, a negative CR propagates more widely than a positive $\mathrm{CR}$, meaning that potential consumers account for the majority of consumers, the number of followers tends to be 0 , and the number of resisters tends to be constant and less than the number of potential consumers.

Let $\quad \varepsilon=1, \alpha=0.003, \beta=0.004, \gamma=0.001, \mu=0.045$. According to equation (11), we have $R_{02}=1.3043>1$. Then, Figure 5 depicts the instability of system (1) about $E_{2}$. In this case, the positive reputation of the corporation propagates more widely than the negative, meaning that the number of potential consumers is close to and larger than that of 


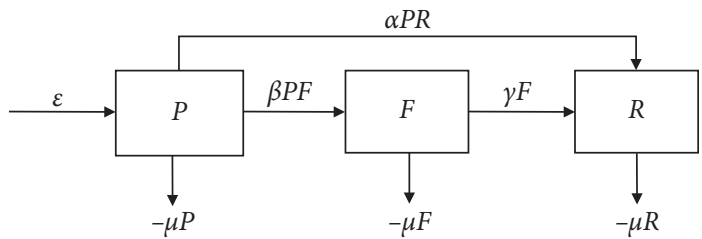

Figure 1: Flow diagram of the model. P: potential customer; F: follower; R: resister.

TABLE 1: Main notations used in the paper.

\begin{tabular}{lc}
\hline Parameters & Description \\
\hline$N$ & Total population of a region \\
$P$ & Number of potential consumers \\
$F$ & Number of followers \\
$R$ & Number of resisters \\
$\varepsilon$ & Recruitment of potential consumers \\
$\alpha$ & Probability that a potential consumer turns into a new resister \\
$\beta$ & Probability that a potential consumer turns into a new follower \\
$\gamma$ & Probability that a follower turns into a new resister \\
$\mu$ & Emigration rate of each class \\
\hline
\end{tabular}

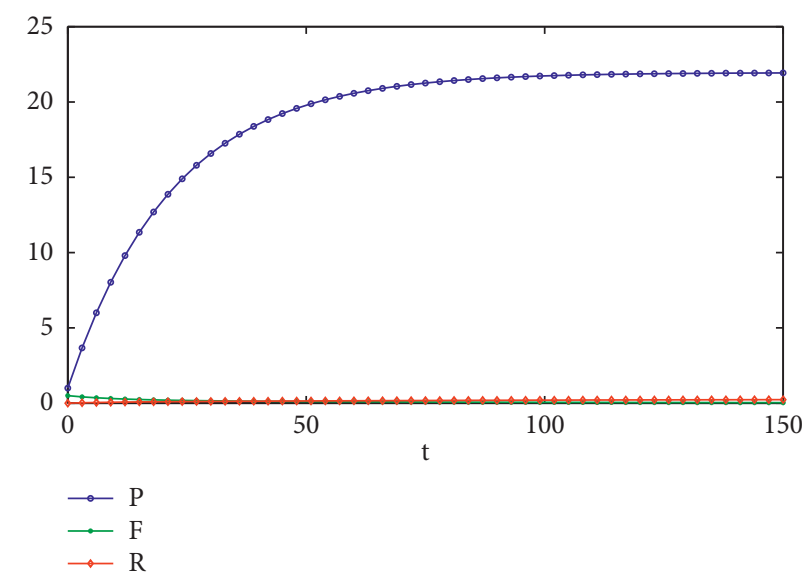

FIgURE 2: The stability of system (1) about $E_{1}$.

followers, and both account for the majority of consumers. The number of resisters tends to be a relatively small constant value.

In Figure 4, the propagation of CR lies in the stability of the system; the number of followers increases slightly and then dwindles to nearly 0 . However, no corporation wants to see the number of followers dropping sharply and the number of resisters soaring. Therefore, the value of $R_{02}$ should be bigger. When $R_{02}=1.3043$ (Figure 5), the result shows that the number of followers rises rapidly. The value of $R_{02}$ is mainly determined by $\alpha, \beta$, and $\gamma$. Thus, a corporation should improve the propagation of positive CR and restrict the propagation of negative CR through sWOM. For example, as shown in Figure 4, some users realize that they have these needs after a corporation develop a new product, the number of potential consumers grows sharply, and some potential consumers become fans, but products often fail in use, so the number of fans of this corporation gradually decreases and to be resisters as time goes on. The result is expected by corporations. However, Figure 5 shows another situation. Users realize that they have these needs after a corporation develops a new good product, many potential consumers are becoming fans, and the number of potential consumers and fans has reached a steady state over time. Each corporation hopes so.

4.3. Instability of the System about $E_{3}$ with Different Parameter Values. Let the parameters take two sets of values that satisfy the conditions of Theorem 3 and Theorem 4, respectively. The numerical simulation results are shown in Figure 6. In this case, over time, the numbers of potential (neutral) consumers and resisters will tend to be constant, and the number of followers will finally tend to be 0 .

As shown in Figure 6(a), because of bad CR, for example, comments on poor product quality are propagated on social 


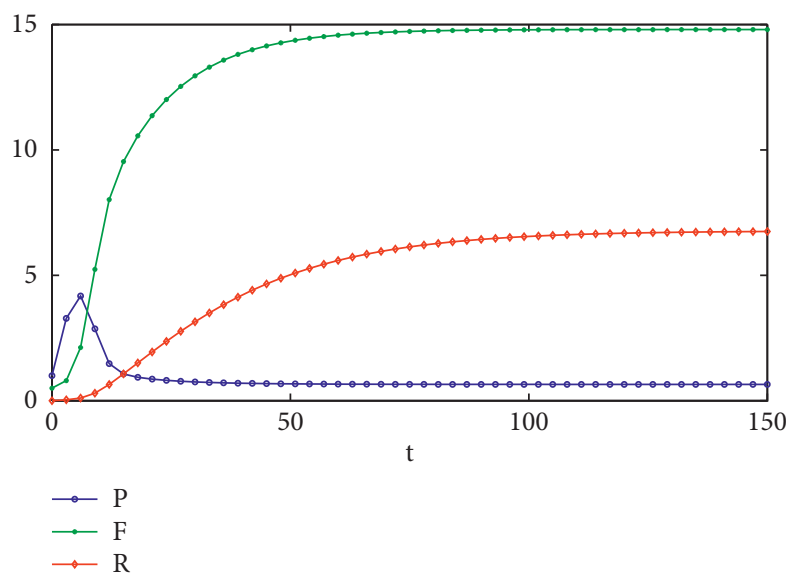

FIgURE 3: The instability of system (1) about $E_{1}$.

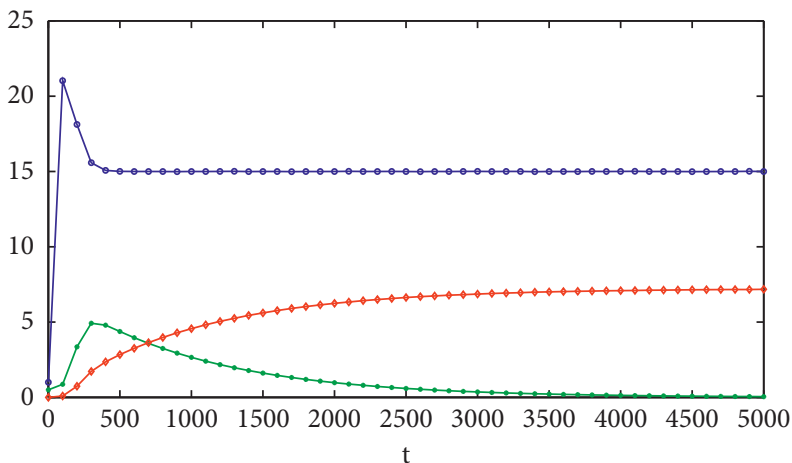

$\rightarrow \mathrm{P}$

$\rightarrow \mathrm{F}$

$\rightarrow \mathrm{R}$

Figure 4: The stability of system (1) about $E_{2}$.

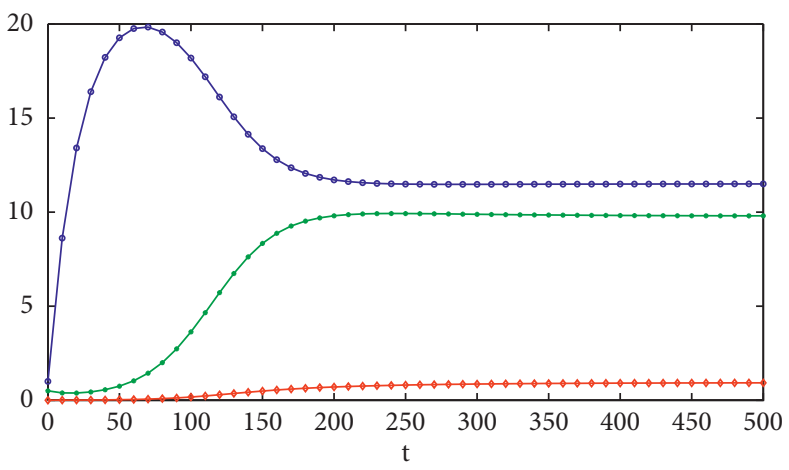

$\because \mathrm{P}$
$\rightarrow \mathrm{F}$
$\rightarrow \mathrm{R}$

FIgURE 5: The instability of system (1) about $E_{2}$.

media platforms, part of potential consumers become resisters directly and part of potential consumers observe neutral. The number of potential (neutral) consumers and resisters goes into a steady state.
As shown in Figure 6(b), because of bad CR, part of potential consumers become resisters directly and part of potential consumers observe neutral. The number of potential (neutral) consumers and resisters goes into a steady 


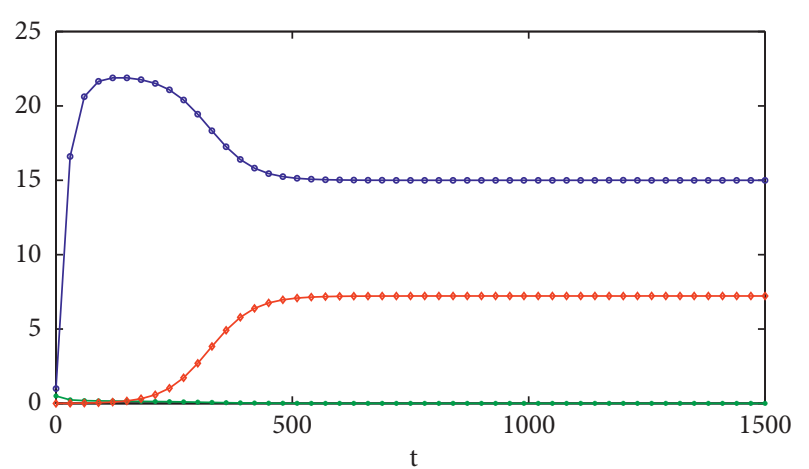

$\multimap$
$\because \mathrm{P}$
$\multimap \mathrm{R}$

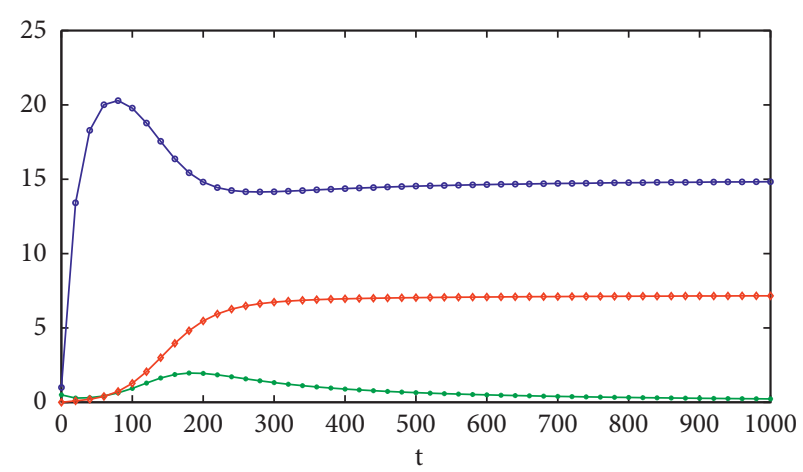

$\multimap$ P
$\because \mathrm{F}$
$\because \mathrm{R}$

(a)

(b)

FIgURE 6: The instability of system (1) about $E_{3}$ with different parameter values. (a) $\varepsilon=1, \alpha=0.003, \beta=0.002, \gamma=0.001, \mu=0.045$. (b) $\varepsilon=1, \alpha=0.003, \beta=0.004, \gamma=0.016, \mu=0.045$.

state in final. For example, in the process, the corporation improved its products and fans increase, but products are used for a period of time and found that they still have some problem and fans become resisters.

As shown in Figure 6, they may use AHP-GDM and fuzzy cluster to analyze reputation crisis [45, 46] when corporations face reputation crisis. Different crisis management schemes are adopted for different crises.

\section{Conclusions and Discussion}

According to the previous analysis, the basic reproduction number can be seen to be a key threshold of CR propagation. Based on the analysis of two basic reproduction numbers and the numerical simulation, system stability is not what corporations aim to see in the propagation of positive CR; on the contrary, stability is what corporations expect in the propagation of negative CR. A corporation hopes to propagate its positive reputation widely and increase public awareness. If a corporation can provide a good user perception and experience, then it will gain more followers. Specifically, differences across channels [47], corporate social responsibility [48-50], online product information, the sincerity of corporations, other consumers' attitudes, and user-generated content $[51,52]$ may affect user perception [53]. Haier Group is a very interesting example. It mines users' demand on product community [54], provide consumer satisfied products, and win positive CR.

Another important conclusion is that sWOM is an important stage in which potential consumers contact followers, as some of these may turn into followers. Customer engagement behaviors are very important. Many companies launch initiatives to stimulate customer engagement $[55,56]$. Corporations should increase the influence of their followers, improve conversion rates, expand the popularity of followers, and actively explore opinion leaders (OLs) [27] and key opinion consumers (KOCs) [57] as an important online marketing resource. The boundaries of corporations should be opened. Corporations should consider OLs as important members of their teams to realize symbiosis and create win-win situations for corporations and OLs. For instance, the company $\mathrm{Mi}$ and its followers create value together; Mi invites its followers to engage in the entire product life cycle. Mi creates the MIUI system, which makes full use of the followers' ability to make improvements to the utility of the system in China. Mi has built a network community in Mi ecology to explore the value of followers. The good dynamic matching between product design and user demand has allowed the sales of $\mathrm{Mi}$ to reach new heights [58]. Additionally, resisters can affect the purchase intention of potential consumers and even followers. Thus, corporate entities should build a public relations crisis department to control the propagation of negative reputation.

In practice, the results in our study could be used to guide corporations to manage CR scientifically and its propagation process, and our work explores a new path, enriches research methods, and provides quantitative prediction and decision support technology for reputation process management. CR will be displayed to corporations from a more intuitive and visual perspective, meaning that corporations operators can have a clearer understanding of CR propagation based on our PFR model. Corporations should develop and discover opinion leaders (OLs) and micro social media influencers $[27,28]$ and construct opinion leaders network with opinion dynamics models and social media networks [59]. It is suggested that corporations should understand the concept of social media deeply and make good use of it $[60,61]$. All online interaction tools belong to the category of social platforms and are channels of CR propagation. Corporations should choose optimal CR propagation channels for their businesses. For example, a corporation has in-depth interaction and communication with users to obtain good CR, it can show more details about product by social media to build CR, allow the user to know and see productive process and transportation route, and take part in product design by social media during the whole production circle including requirement investigation, functional design, function optimization, product concept, product sample, product trial, user feedback, product optimization, production, sales, and transportation path. These 
behaviors improve the honesty of the corporation and attract potential consumers to upgrade to its fans. Else, some corporations still are giving to charity. They make more people know their benevolence by a large social media platform and win more respect and love from users; many potential consumers actively buy their products and make more people know their good CR.

Our study is not without limitations. One limitation lies in the simplification of the PFR model parameters for CR propagation when deriving the analytically tractable results. Another limitation is that we chose to omit some consumer attribute variables (such as age and gender) to focus on the process of CR propagation. One promising area for future work is the incorporation of consumer attributes into the PFR model to see whether the main findings in the present study still hold. Another topic for future study is the investigation of whether the findings in this study could be generalized to other business settings, such as key element construction in the strategic planning of ecological brand reputation. At a higher level, another avenue for future work is research into the PFR propagation model with the blockchain.

\section{Data Availability}

Data sharing is not applicable in this paper as no datasets were generated or analyzed during the current study.

\section{Conflicts of Interest}

The authors declare no conflicts of interest.

\section{Authors' Contributions}

Conceptualization was contributed by Y. W. and X. Y.; methodology was designed by Y. C. and Xg. Y.; software provision, formal analysis, investigation, original draft preparation, and reviewing and editing were performed by Y. W. and Y. C.; validation and funding acquisition were conducted by Y. C.; visualization was performed by Y. C. and Q. T.; supervision was carried out by X. Y.; project administration was performed by Y. C. All authors have read and agreed to the published version of the manuscript.

\section{Acknowledgments}

This research was funded by Humanities and Social Sciences Research Planning Fund of the Ministry of Education of China (Grant no. 19YJA630015), Natural Science Foundation of Heilongjiang Province of China (Grant no. LH2019G005), National Natural Science Foundation of China (Grant no. 61801141), Doctoral Fund Project of Longdong University (Grant no. XYBY202001), and the Fundamental Research Funds for the Central Universities.

\section{References}

[1] J. Wei, Z. Ouyang, and H. A. Chen, "Well known or well liked? The effects of corporate reputation on firm value at the onset of a corporate crisis," Strategic Management Journal, vol. 38, no. 10, pp. 2103-2120, 2017.
[2] A. Brady and O. Kristjan, "The sustainability effect: rethinking corporate reputation in the 21st century," Sustainability Effect Rethinking Corporate Reputation in Century, vol. 38, no. 3, 2005.

[3] D. L. Deephouse, "Media reputation as a strategic resource: an integration of mass communication and resource-based theories," Journal of Management, vol. 26, no. 6, pp. 1091-1112, 2000.

[4] H. Rao, "The social construction of reputation: certification contests, legitimation, \& the survival of organizations in the American automobile industry: 1895-1912," Strategic Management Journal, vol. 15, no. Winter, pp. 29-44, 1994.

[5] P. W. Roberts and G. R. Dowling, "Corporate reputation and sustained superior financial performance," Strategic Management Journal, vol. 23, no. 12, pp. 1077-1093, 2002.

[6] C. J. Fombrun, The Building Blocks of Corporate Reputation: Definitions, Antecedents, Consequences, Oxford Handbooks, 2012.

[7] O. Turel, A. Serenko, and N. Bontis, "User acceptance of hedonic digital artifacts: a theory of consumption values perspective," Information \& Management, vol. 47, no. 1, pp. 53-59, 2010.

[8] We Are Social and Hootsuite. Digital 2020 Reports, https:// wearesocial.com/blog/2020/01/digital-2020-3-8-billion-peopleuse-social-media, 2020.

[9] N. T. Wood and C. K. S. Muñoz, How to Mobilize Social Word of Mouth (sWOM), 2017.

[10] C. Ferro-Soto, L. A. Macías-Quintana, and P. VázquezRodríguez, "Effect of stakeholders-oriented behavior on the performance of sustainable business," Sustainability, vol. 10, no. 12, 2018.

[11] M. C. Tina and W. D. Marcia, "The power of social media and its influence on corporate reputation," in The Handbook of Communication and Corporate Reputation, pp. 497-512, Wiley, Hoboken, NJ, USA, 2014.

[12] M. Etter, D. Ravasi, and E. Colleoni, "Social media and the formation of organizational reputation," Academy of Management Review, vol. 44, no. 1, pp. 28-52, 2019.

[13] A. M. Casado, "A perception group decision model to evaluate corporate reputation," in Proceedings of the 2013 Xxxix Latin American Computing Conference (CLEI), Caracas, Venezuela, October 2013.

[14] A. Babić Rosario, F. Sotgiu, K. De Valck, and T. H. A. Bijmolt, "The effect of electronic word of mouth on sales: a metaanalytic review of platform, product, and metric factors," Journal of Marketing Research, vol. 53, no. 3, pp. 297-318, 2016.

[15] S.-B. Kim and D.-Y. Kim, “Antecedents of corporate reputation in the hotel industry: the moderating role of transparency," Sustainability, vol. 9, no. 6, 2017.

[16] L. Liu, M. K. O. Lee, R. Liu, and J. Chen, “Trust transfer in social media brand communities: the role of consumer engagement," International Journal of Information Management, vol. 41, pp. 1-13, 2018.

[17] Q. Yan, “A system dynamics model of online stores' sales: positive and negative E-WOM and promotion perspective," Sustainability, vol. 11, no. 21, 2019.

[18] N. L. Williams, "From WOM to aWOM-the evolution of unpaid influence: a perspective article," Tourism Review, vol. 75, no. 1, pp. 314-318, 2019.

[19] A. Serra Cantallops and F. Salvi, "New consumer behavior: a review of research on eWOM and hotels," International Journal of Hospitality Management, vol. 36, pp. 41-51, 2014. 
[20] L. M. C. Suarez, "The influence of heuristic judgments in social media on corporate reputation: a study in Spanish leader corporations," Sustainability, vol. 12, no. 4, 2020.

[21] S. Kim, J. Kandampully, and A. Bilgihan, "The influence of eWOM communications: an application of online social network framework," Computers in Human Behavior, vol. 80, pp. 243-254, 2018.

[22] J. Huibers and J. Verhoeven, "Webcare als online reputatiemanagement," Tijdschrift voor Communicatiewetenschap, vol. 42, no. 2, pp. 165-+, 2014.

[23] J. Brown, A. J. Broderick, and N. Lee, "Word of mouth communication within online communities: conceptualizing the online social network," Journal of Interactive Marketing, vol. 21, no. 3, pp. 2-20, 2007.

[24] C. M. K. Cheung and D. R. Thadani, "The impact of electronic word-of-mouth communication: a literature analysis and integrative model," Decision Support Systems, vol. 54, no. 1, pp. 461-470, 2012.

[25] Y. Gvili and S. Levy, "Antecedents of attitudes toward eWOM communication: differences across channels," Internet Research, vol. 26, no. 5, pp. 1030-1051, 2016.

[26] S.-C. Chu and Y. Kim, "Determinants of consumer engagement in electronic word-of-mouth (eWOM) in social networking sites," International Journal of Advertising, vol. 30, no. 1, pp. 47-75, 2011.

[27] H. Haron, E. H. Johar, and Z. F. Ramli, "Online opinion leaders and their influence on purchase intention," in Proceedings of the 2016 IEEE Conference on e-Learning, e-Management and e-Services (IC3e), pp. 162-165, Langkawi, Malaysia, October 2016.

[28] S. Kay, R. Mulcahy, and J. Parkinson, "When less is more: the impact of macro and micro social media influencers' disclosure," Journal of Marketing Management, vol. 36, no. 3-4, pp. 248-278, 2020.

[29] R. Filieri, "What makes online reviews helpful? A diagnosticity-adoption framework to explain informational and normative influences in e-WOM," Journal of Business Research, vol. 68, no. 6, pp. 1261-1270, 2015.

[30] M. Joshi and M. McKendall, "Responses to the discovery of unethical acts: an organizational identity and reputation perspective," Business \& Society, vol. 57, no. 4, pp. 706-741, 2018.

[31] D. C. DeAndrea, B. Van Der Heide, M. A. Vendemia, and M. H. Vang, "How people evaluate online reviews," Communication Research, vol. 45, no. 5, pp. 719-736, 2018.

[32] M. Gannon, B. Taheri, and H. Olya, "Festival quality, selfconnection, and bragging," Annals of Tourism Research, vol. 76, pp. 239-252, 2019.

[33] S. Molinillo, "Analyzing the effect of social support and community factors on consumer engagement and its impact on loyalty behaviors toward social commerce websites," Computers in Human Behavior, vol. 108, p. 12, 2020.

[34] A. T. Vercic and D. S. Coric, "The relationship between reputation, employer branding and corporate social responsibility," Public Relations Review, vol. 44, no. 4, pp. 444-452, 2018.

[35] T. Daddi, F. Iraldo, F. Testa, and M. R. De Giacomo, "The influence of managerial satisfaction on corporate environmental performance and reputation," Business Strategy and the Environment, vol. 28, no. 1, pp. 15-24, 2019.

[36] B. Lowe and F. Alpert, "Antecedents and consequences of consumer perception of product innovativeness," in Looking Forward, Looking Back: Drawing on the Past to Shape the Future of Marketing. Developments in Marketing Science:
Proceedings of the Academy of Marketing Science, C. Campbell and J. Ma, Eds., Springer, Cham, Switzerland, 2016.

[37] W. H. Chih, "The antecedents and consequences of the perceived positive eWOM review credibility," Industrial Management \& Data Systems, vol. 120, no. 6, pp. 1217-1243, 2020.

[38] M. A. A. Dewi, I. Nurrohmah, N. Sahadi, D. I. Sensuse, and H. Noprison, "Analysing the critical factors influencing consumers' e-impulse buying behavior," in Proceedings of the 2017 International Conference on Advanced Computer Science and Information Systems (ICACSIS), pp. 81-92, Bali, Indonesia, October 2017.

[39] H. Khan and V. Sukhotu, "Influence of media exposure and corporate social responsibility compliance on consumer perception: the moderating role of firm's reputation risk," Corporate Social Responsibility and Environmental Management, vol. 27, no. 5, pp. 2107-2121, 2020.

[40] P. K. Kannan and H. A. Li, "Digital marketing: a framework, review and research agenda," International Journal of Research in Marketing, vol. 34, no. 1, pp. 22-45, 2017.

[41] https://www.youtube.com/watch?v=wvKof51MM8s.

[42] T. van Laer, "What happens in vegas stays on TripAdvisor? A theory and technique to understand narrativity in consumer reviews," Journal of Consumer Research, vol. 46, no. 2, pp. 267-285, 2019.

[43] P. Dreessche and J. Watmough, "Reproduction numbers and sub-threshold endemic equilibria for compartmental models of disease transmission," Mathematical Biosciences, vol. 180, no. 1-2, pp. 29-48, 2002.

[44] O. Diekmann, J. A. Heesterbeek, and J. A. Metz, "On the definition and the computation of the basic reproduction ratio R0 in models for infectious-diseases in heterogeneous populations," Journal of Mathematical Biology, vol. 28, no. 4, 1990.

[45] C. S. Lin, G. Kou, Y. Peng, and F. E. Alsaadi, “Aggregation of the nearest consistency matrices with the acceptable consensus in AHP-GDM," Annals of Operation Research, vol. 3, 2020.

[46] L. Guangxu, K. Gang, and P. Yi, "Heterogeneous large-scale group decision making using fuzzy cluster Analysis and its application to emergency response plan selection," IEEE Transactions on Systems, Man and Cybernetics: Systems, vol. 4, 2021.

[47] R. Lozano, "A holistic perspective on corporate sustainability drivers," Corporate Social Responsibility and Environmental Management, vol. 22, no. 1, pp. 32-44, 2015.

[48] S. P. Saeidi, S. Sofian, P. Saeidi, S. P. Saeidi, and S. A. Saaeidi, "How does corporate social responsibility contribute to firm financial performance? The mediating role of competitive advantage, reputation, and customer satisfaction," Journal of Business Research, vol. 68, no. 2, pp. 341-350, 2015.

[49] M. Taghian, C. D'Souza, and M. Polonsky, “A stakeholder approach to corporate social responsibility, reputation and business performance," Social Responsibility Journal, vol. 11, no. 2, pp. 340-363, 2015.

[50] J. Benitez, "How corporate social responsibility activities influence employer reputation: the role of social media capability," Decision Support Systems, vol. 129, 2020.

[51] I. Confente, G. G. Siciliano, B. Gaudenzi, and M. Eickhoff, "Effects of data breaches from user-generated content: a corporate reputation analysis," European Management Journal, vol. 37, no. 4, pp. 492-504, 2019. 
[52] Y. Wang, G. Berens, C. B. M. van Riel, and B. M. Cees, "Competing in the capital market with a good reputation," Corporate Reputation Review, vol. 15, no. 3, pp. 198-221, 2012.

[53] K. Freberg, Social Media for Strategic Communication: Creative Strategies and Research-Based Application, p. 180, SAGE publication, Thousand Oaks, CA, USA, 2018.

[54] F. Wang, X. Wang, and C. Zhang, "Ultra-modular architecture in platform and customized support for intrapreneurship: an embedded case study of haier's transformation to platform organization," Management World, vol. 35, no. 2, pp. 121-150, 2019.

[55] S. F. M. Beckers, "Good, better, engaged? The effect of company-initiated consumer engagement behavior on shareholder value," Journal of the Academy of Marketing Science, vol. 46, no. 3, pp. 366-383, 2020.

[56] W. Huang, "The study on the relationships among film fans' willingness to pay by film crowdfunding and their influencing factors," Economic Research-Ekonomska Istraživanja, vol. 33, no. 1, pp. 804-827, 2020.

[57] B. L. Shen, "Optimization of key opinion consumer selection strategy for corporation in the internet environment," Management Science and Engineering, vol. 8, pp. 368-375, 2019.

[58] L. Song, Y. Song, and S. Feng, "Platform-community business model: based on the case of haier platform organization, $\mathrm{Mi}$ network community and ZBJ. COM crowdsourcing platform," Business Management Journal, vol. 42, no. 3, pp. 117-132, 2020.

[59] Q. B. Zha, G. Kou, H. J. Zhang et al., "Opinion dynamics in finance and business: a literature review and research opportunities," Financial Innovation, vol. 6, no. 1, 2021.

[60] H. Kim and B. Chang, "A study on the effects of crowdfunding values on the intention to visit local festivals: focusing on mediating effects of perceived risk and e-WOM," Sustainability, vol. 12, no. 8, 2020.

[61] E. J. Seo, "The effect of social media usage characteristics on e-WOM, trust, and brand equity: focusing on users of airline social media," Sustainability, vol. 12, no. 4, p. 1691, 2020. 